\title{
Monitoring of Drought in Central Yunnan, China Based on TVDI Model
}

\author{
Huan Deng ${ }^{1,2,3,4,5}$, Feng Cheng ${ }^{1,2,3,4 *}$, Jinliang Wang ${ }^{1,2,3,4}$, Cheng Wang ${ }^{1}$ \\ ${ }^{1}$ Faculty of Geograghy, Yunnan Normal University, Kunming, Yunnan 650500, China \\ ${ }^{2}$ Key Laboratory of Remote Sensing for Resources and Environment of Colleges and Universities of Yunnan Province, \\ Kunming, Yunnan 650500, China \\ ${ }^{3}$ Yunnan Geospatial Information Technology Engineering Technology Research Center, Kunming 650500, China \\ ${ }^{4}$ Yunnan University Science and Technology Innovation Team, Kunming 650500, China \\ ${ }^{5}$ School of Geographical Sciences and Tourism, Zhaotong University, Zhaotong, Yunnan 657000, China
}

Received: 3 June 2020

Accepted: 27 November 2020

\begin{abstract}
Central Yunnan, constantly in a state of water shortage, is a region of fragile ecological environment whose regional agricultural production and economic development are seriously restricted by drought, despite its relatively developed social economy and dense population. In order to study the drought situation in this area, Landsat TM $\backslash$ OLI remote sensing image data of the region in 2008, 2011, 2014, and 2017 was selected for the construction of the NDVI-LST characteristic space temperature vegetation drought index (TVDI) using the normalized difference vegetation index (NDVI) and the land surface temperature (LST). The validity of TVDI was verified by Standardized Precipitation Index (SPI), Palmer Drought Severity Index (PDSI) and Potential Evapotranspiration (PET), and the TVDI calculation results were divided into 5 drought levels: wet, normal, moderately dry, dry and severe dry. It is shown that: (1) The TVDI values of different land use types have obvious changes and good applicability; (2) TVDI can effectively reflect the characteristics of drought and spatial-temporal changes in central Yunnan, and the severe drought is mostly distributed in the west and southwest; (3) In the past 10 years, the dynamics of drought in this area have changed significantly, mainly from drought to slight drought, and the overall drought has decreased with time. It is concluded that TVDI model accurately reflected the drought situation in central Yunnan and thus is an instructive tool for regional drought monitoring.
\end{abstract}

Keywords: drought monitoring, TVDI, SPI, central Yunnan

\section{Introduction}

Drought refers to the phenomenon that water quantity cannot meet the normal demand, which is

*e-mail: chengfeng_rs@163.com disadvantageous to the urban and rural life and the industrial production, agriculture and animal husbandry [1]. It has the characteristics of wide distribution and long duration. Drought is one of the most serious natural disasters in agricultural production in China [2]. Therefore, the effective monitoring of drought is related to China's food security and the development of the national economy. 
Drought monitoring is mainly carried out by traditional methods and remote sensing methods. The traditional drought monitoring method, which is based on the drought data collected at the site and applies to small areas, lacks the drought typicality of spatial region [3], thus with which it is difficult to achieve comprehensive and effective drought monitoring. Remote sensing is an important means of agricultural drought monitoring whose space remote sensing technology compensates for the shortcomings of traditional monitoring because of its advantage of rapid acquisition of spectral information of large areas of ground objects in time and space [4]. With the development of drought monitoring research, great progress has been made in the use of remote sensing in large-scale drought monitoring research and the effectiveness of drought monitoring research results has increased significantly [5]. The research methods and indicators have tended to be diversified and systematic, including integrated monitoring model, microwave remote sensing monitoring method, vegetation index, monitoring method and temperature based monitoring method, and each has its advantages and disadvantages.

The temperature vegetation drought index (TVDI) is a two-dimension featured spatial drought index based on vegetation index (NDVI) and surface temperature (LST). Vegetation index is used to evaluation of vegetation cover, growth status and biomass as a reflection of surface vegetation cover and growth. It is the most commonly used vegetation index, in spite of its sensitivity to changes in soil background, because it is able to eliminate most of the irradiance changes related to instrument calibration, solar angle, topography, cloud shadow and atmospheric conditions and responds better to vegetation. Temperature is an important condition for agricultural production and is often used as an indicator of meteorological drought monitoring. It is closely related to evapotranspiration of surface water, vegetation growth, changes of global climate and human life, and is an indispensable parameter in geographical environment research. Thermal infrared band of remote sensing data was used in surface temperature inversion for calculation of surface radiation temperature value with a variety of methods, for it does not damage the surface thermodynamic state. It has been affirmed by many scholars in regional agricultural drought monitoring [6-11] that TVDI, which indicates both the change of the normalized difference vegetation index (NDVI) in the study area and the change of the land surface temperature (LST) under the same conditions of the NDVI, is a mature and widely used technology for regional drought monitoring.

Han et al. [10] used the HJ-1A/1B satellite Poyang Lake watershed to construct NDVI-LST space from March to June 2011, calculated the TVDI of Poyang Lake watershed, and verified the reliability of TVDI using the AMSR-E surface soil moisture data observed simultaneously. Yan et al. [11] used the MODIS product data and the relative soil water content RSM data to study the difference of remote sensing monitoring of spatial drought in Ts-EVI characteristics of Hebei Province at multiple time scales, the results of drought monitoring showed good consistency in spatial distribution.

Though located in the upper reaches of Yangtze River, Pearl River and Red River near Dianchi Lake, Fuxian Lake and other plateau lakes, central Yunnan suffers from uneven water spatial distribution, serious water shortage and frequent spring droughts in spite of its high degree of water resources guarantee. As a result, the region struggles in damaged ecological environment and great losses in industrial and agricultural production and social and economic development. Therefore, it is of important practical significance for the early warning

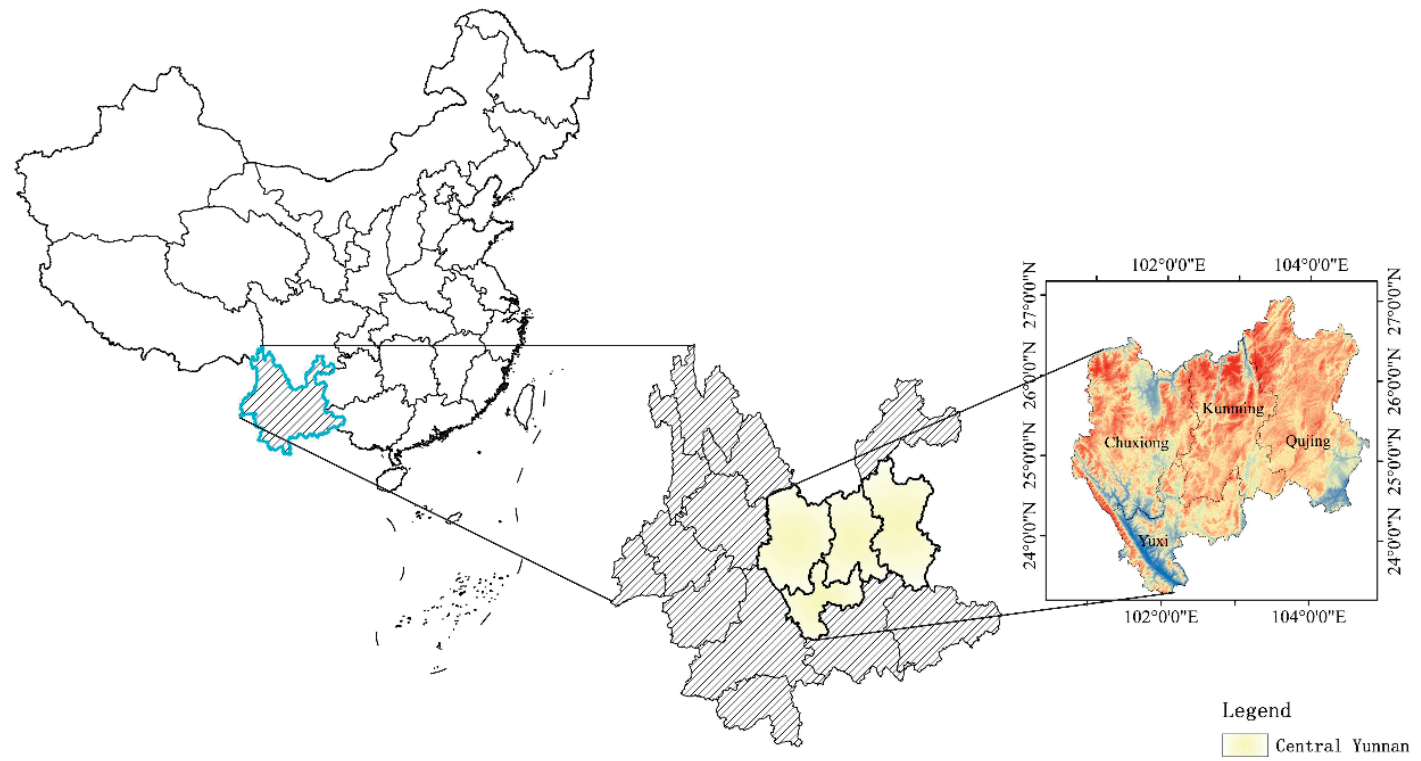

Fig. 1.The study area. 
of drought in this region and the production and life in the future to invert the regional drought degree using remote sensing data and monitor and analyze the trend of temporal and spatial distribution of drought in the region from 2008 to 2017.

\section{Description of the Study Area}

Central Yunnan area covers a land span of $23^{\circ} 19^{\prime} \sim 27^{\circ} 03^{\prime} \mathrm{N}, 100^{\circ} 43^{\prime} \sim 104^{\circ} 50^{\prime} \mathrm{E}$. The administrative district includes four prefectures of KunmingCity, QujingCity, ChuxiongCity and YuxiCity, involving about 50 counties (cities), covering an area of about 100,000 square kilometers (Fig. 1). Its population accounts for $1 / 3$ of Yunnan province, the gross domestic product (GDP) is $1 / 2$ of the province, the gross output value of industry and agriculture $2 / 3$, the gross industrial output value $4 / 5$, and the grain output $1 / 3$. The area is dominated by mountainous and inter-mountain basin topography, with undulating terrain and subtropical plateau monsoon climate. The central Yunnan Plateau is a part of the source of the Pearl River. The karst and rocky desertification are widely distributed and the ecological environment is fragile. Due to the influence of meteorological climate, topography and geomorphology and human being on the underlying surface, less rainfall in winter and spring, large evaporation and frequent drought lead to serious water shortage and restrict the development of industry, agriculture and social economy (Fig. 1).

\section{Data Sources and Research Methods}

\section{Data Sources and Processing}

It is of great significance to monitor the spatial and temporal variation of drought in central Yunnan where spring drought frequently occurs over the past 10 years. A total of 44 remote sensing images were

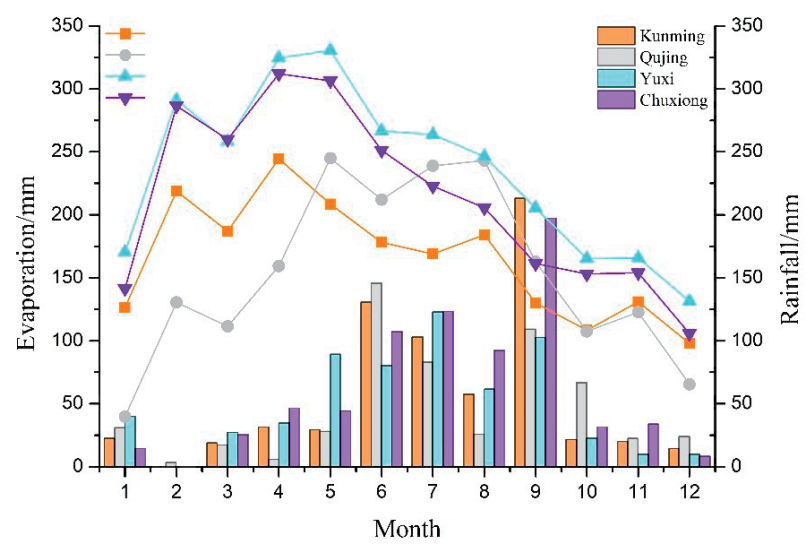

Fig. 2. Changes in rainfall and evaporation in Kunming, Qujing, Yuxi and Chuxiong stations in 2011. selected from 2008, and 2011 (Landsat5 TM), 2014 and 2017 (Landsat8 OLI) with a spatial resolution of $30 \mathrm{~m}$, acquisition time from February to September (as shown in Fig. 2), the drought in the study area was mainly spring drought, and the selected months are mainly from February to May, subject to the influence of Landsat data resolution and cloud cover. Two image data from June and September 2011 were used to ensure the integrity of the study area.), UTM map projection, and earth ellipsoid WGS-84. Remote sensing data source was Geospatial data clouds (http:// www.gscloud.cn/) and USGS (https://www.usgs. gov/). ENVI software was used to preprocess remote sensing image data, including radiometric calibration (Radiance), atmospheric correction (FLAASH), splicing, clipping, water and cloud extraction, etc. Meteorological data mainly include monthly average rainfall, sunshine hours, average temperature, average maximum temperature, average minimum temperature, average wind speed, and average water vapor pressure data. Main data sources are Yunnan Meteorological Bureau, statistical yearbooks of 4 cities and prefectures and China Meteorological Data Network (http://data. $\mathrm{cma} . \mathrm{cn} /$ ).

\section{Research Methods}

In this paper, method (TVDI) based on the characteristic space of surface temperature-vegetation index is adopted. The preprocessing of remote sensing data mainly includes the calculation of vegetation index, brightness temperature, and surface specific emissivity. The atmospheric correction method (radiation transfer equation) is used to invert the surface temperature to construct the characteristic space by using the obtained vegetation index and surface temperature. And the TVDI model is obtained according to the maximum and minimum value fitting the dry and wet edge equation of the feature space. The applicability of the TVDI model in the study area is indirectly verified on the basis of the classification of the drought in central Yunnan according to TVDI value and the correlation analysis using meteorological data and temperature vegetation drought index.

\section{Extraction of Water Bodies and Clouds}

Due to the fact that water and clouds are the important factors influencing the precision of land surface temperature inversion, it was necessary to carry out major water and cloud extraction and mask processing for a high quality of the LST retrieval precision and TVDI. The method of supervised classification was adopted for the land classification in central Yunnan by a support vector machine (SVM) classifier to divide the study area into three categories: clouds, water, and others, before water and cloud mask files were constructed for the above mentioned mask processing. 


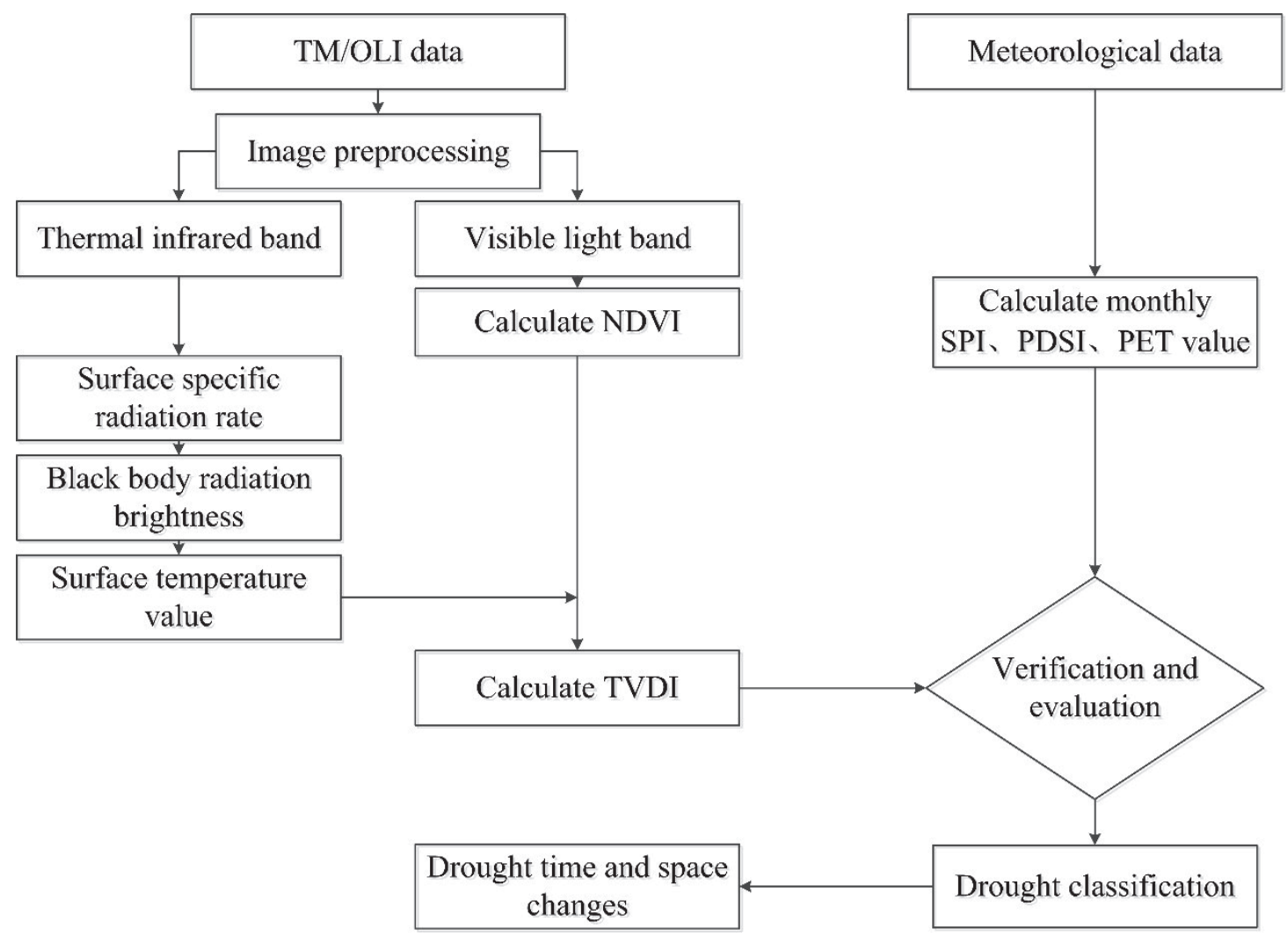

Fig. 3. Technical route.
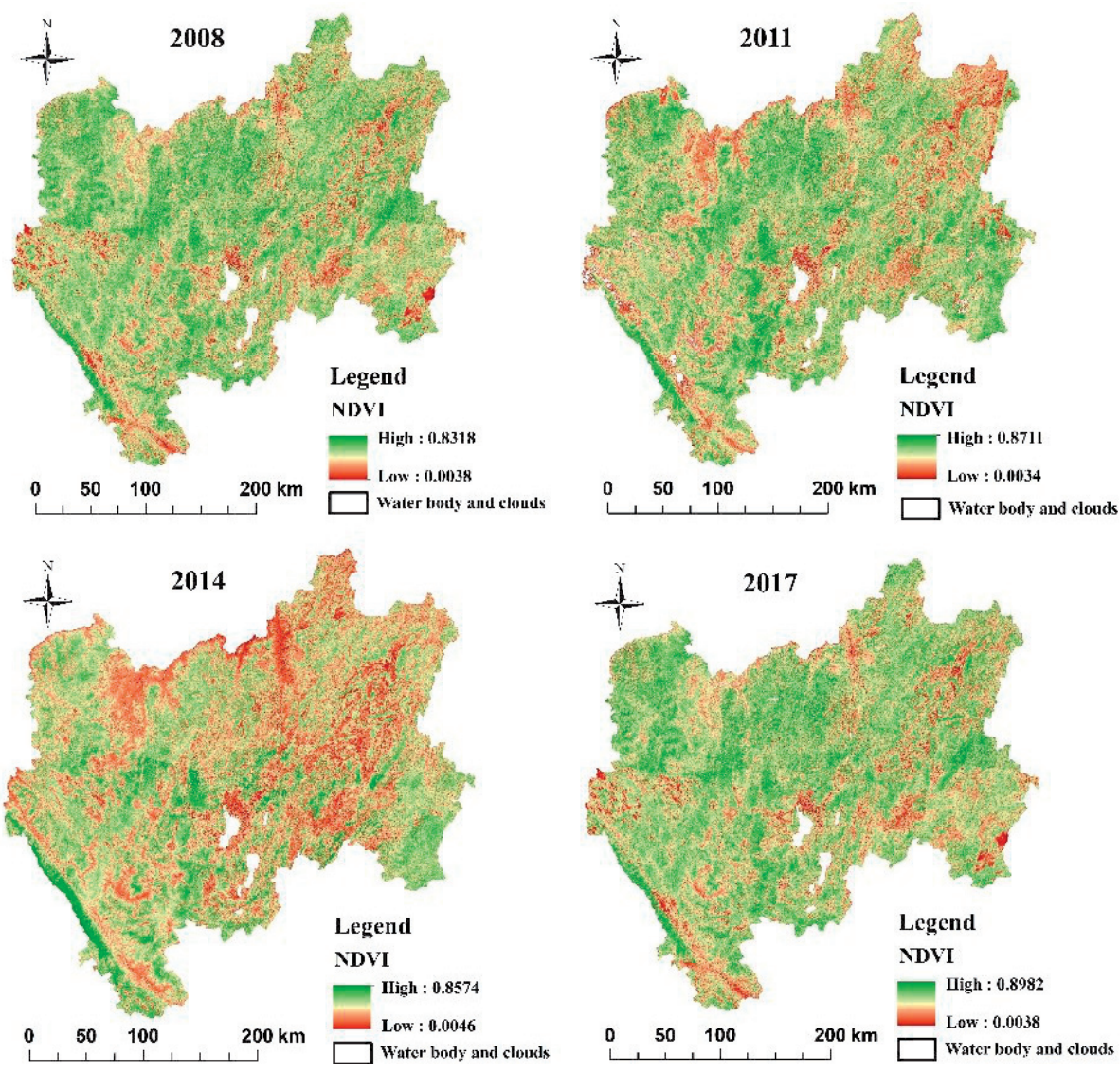

Fig. 4. Masking of water and clouds. 


\section{Normalized Vegetation Index}

NDVI is the most widely used among more than 40vegetation indexes. Fig. 4 shows the NDVI calculation results for each study year in central Yunnan. The formulas are as follows:

$$
N D V I=(N I R-R) /(N I R+R)
$$

...where NIR is the reflectance value in the near-infrared band; $R$ is the reflectance value in the red band. The calculation results of NDVI for each study year in central Yunnan are shown in Fig. 4.

\section{Surface Temperature Inversion}

At present, there are three main types of surface temperature inversion algorithms: single channel algorithm, multi-channel algorithm and split window algorithm. In this paper, the atmospheric correction method based on the thermal radiation conduction equation under the single-channel algorithm is used to invert the surface temperature by using the thermal infrared band b6 of Landsat 5 TM and the thermal infrared band b10 of Landsat 8 OLI data. This method is simple and accurate with high precision. The specific calculation formula is as follows: The expression of the thermal infrared radiance value $L_{\lambda}$ is (radiation transfer equation):

$$
L_{\lambda}=\left[\varepsilon B\left(T_{S}\right)+(1-\varepsilon)\right] \tau+L \uparrow
$$

...where $\varepsilon$ is surface ratio radiance, $T_{S}$ is land surface real temperature $(\mathrm{K}), D\left(T_{S}\right)$ is black body heat radiance, $L \uparrow$ is atmospheric upward radiant energy, $L \downarrow$ is atmospheric downward radiant energy, $\tau$ is atmospheric transmittance in the thermal infrared band (parameter query website: http://atmcorr.gsfc.nasa.gov). The radiance of the black body $D\left(T_{S}\right)$ at temperature $T$ in the thermal infrared band is:

$$
B\left(T_{S}\right)=\left[L_{\lambda}-L \uparrow-\tau(1-\varepsilon) L \downarrow\right] / \tau \varepsilon
$$

$T_{S}$ can be obtained by the function of the Planck formula. The specific formula is:

$$
T_{S}=K_{2} / \ln \left(K_{1} / B\left(T_{S}\right)+1\right)
$$

Among them, $K_{1}=774.89 \mathrm{~W} /\left(\mathrm{m}^{2 *} \mu \mathrm{m} * \mathrm{sr}\right)$, $K_{2}=1311.08 \mathrm{~K}$. The results of surface temperature inversion in central Yunnan are shown in Fig. 5.

\section{Temperature-Vegetation Drought Index}

Based on the relation between vegetation index and surface temperature, Sandholt [12] put forward the drought index of temperature-vegetation. Defined as:
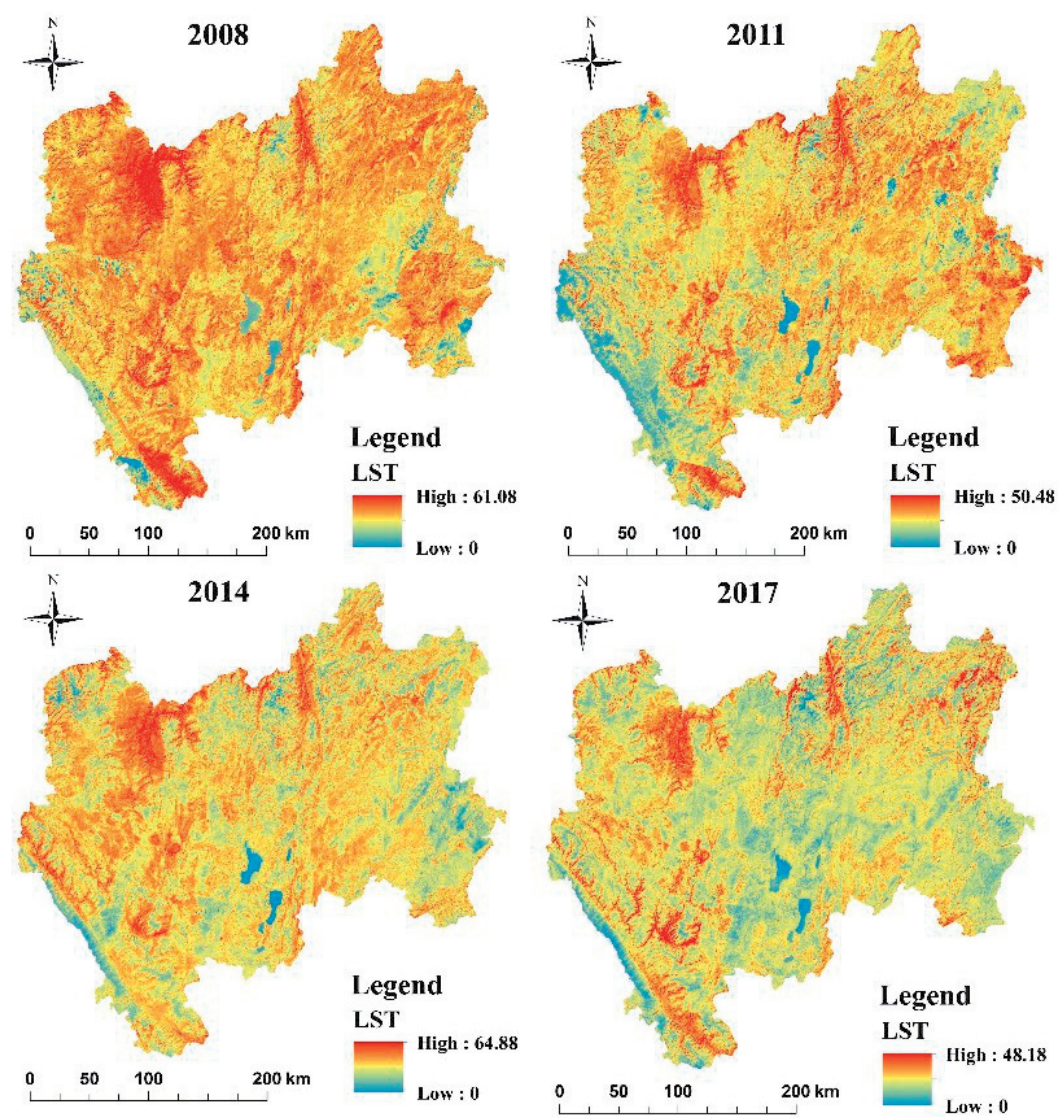

Fig. 5. Spatiotemporal characteristics of surface temperature in central Yunnan from 2008 to 2017. 


$$
T V D I=\left(T_{S}-T_{N D V I . m i n}\right) /\left(T_{N D V I . m a x}-T_{N D V I . m i n}\right)
$$

...where $T_{S}$ is the surface temperature, $T_{\text {NDVI.max }}$ is the maximum ground temperature corresponding to the NDVI value, and the dry-edge fitting equation is:

$$
T_{N D V I . \max }=a+b \times N D V I
$$

...where $T_{\text {NDVImin }}$ is the minimum ground temperature corresponding to the NDVI value, and the wet edge fitting equation is:

$$
T_{N D V I . \min }=c+d \times N D V I
$$

...where a, b, c, and d are the coefficients of the linear fit equation of the dry and wet edges representing the intercept and slope of the dry and wet edges, respectively. The closer $T_{S}$ is to the dry side, the larger the TVDI, indicating that the soil drought is more severe. Conversely, the closer $T_{S}$ is to the wet side, the smaller the TVDI, indicating the higher the soil moisture content. In this way, the correlation between TVDI and soil water content reflected the drought situation. The value of TVDI is between 0 and 1. The larger the TVDI value, the more serious the drought in this area.

\section{Calculation of the Standardized Precipitation Index (SPI)}

SPI was proposed by American scientist McKee [13] utilized regional rainfall data. In the drought grade standard issued by the Ministry of Water Resources of China, it is also pointed out that soil moisture is the main index to judge agricultural drought, and precipitation is the basic index to evaluate the degree of agricultural drought according to the drought grade standard issued by the Ministry of Water Resources of China [14]. The Standardized Precipitation Index (SPI) was used to verify the applicability of the TVDI index in Yunnan. The SPI index uses $\Gamma$ distribution probability to describe the precipitation, and then normalizes the skewed probability distribution. The specific calculation formula is [15]

$$
\mathrm{SPI}=\mathrm{S} \frac{t-\left(c_{2} t+c_{1}\right) t+c_{0}}{\left[\left(d_{3} t+d_{2}\right) t+d_{1}\right] t+1.0}
$$

$$
\text { In the formula: } t=\sqrt{\ln \frac{1}{G(x)^{2}}}
$$

...where $\mathrm{G}(\mathrm{x})$ is the precipitation distribution probability related to the $\Gamma$ function; $\mathrm{X}$ is the precipitation sample value; $\mathrm{S}$ is the positive and negative coefficients of the probability density; $\mathrm{c}_{0}, \mathrm{c}_{1}, \mathrm{c}_{2}$ and $\mathrm{d}_{1}, \mathrm{~d}_{2}, \mathrm{~d}_{3}$ are the $\Gamma$ distribution functions. Formula calculation parameter, the specific value is $\mathrm{c}_{0}=2.515517, \mathrm{c}_{1}=0.802853$, $\mathrm{c}_{2}=0.010328, \mathrm{~d}_{1}=1.432788, \quad \mathrm{~d}_{2}=0.189269$, $\mathrm{d}_{3}=0.001308$.

When $\mathrm{G}(\mathrm{x})>0.5, \mathrm{~S}=1$; When $\mathrm{G}(\mathrm{x}) \leq 0.5, \mathrm{~S}=-1, \mathrm{G}$ (x) can be obtained from the probability density integral formula of $\Gamma$ function, the formula is:

$$
\mathrm{G}(\mathrm{x})=\frac{2}{\beta^{\gamma} \Gamma\left(\gamma_{0}\right)} \int_{0}^{x} x^{\gamma-1} \varepsilon^{-x / \beta} d x, x>0
$$

...where $\beta$ and $\gamma$ are the shape and scale parameters of the $\Gamma$ distribution function.

This paper uses SPI index simulation to obtain the drought index of the region. The value of SPI is -2.0 2.0. The smaller the SPI value, the drier the area, and vice versa. The drought and flood levels are divided into six levels according to the Classification standard issued by the National Climate Center (Table 1).

\section{Palmer Drought Severity Index (PDSI) Calculation}

Palmer [16] proposed the Palmer drought severity index (PDSI) in 1965, which comprehensively considers precipitation, soil water content, runoff and potential evapotranspiration and is widely used in drought monitoring. However, the simple PDSI Thornthwaite method of estimating PDSI over-exaggerates the effect of temperature thus the estimation tends toward dry. Therefore, a more reasonable method is used to calculate the potential evapotranspiration PET (Potential evapotranspiration).This method is the preferred method for calculating possible evapotranspiration proposed by the FAO (Food and Agriculture Organization of United Nations). It does not require regional revisions or changes in any parameters. It has strong regional applicability and its calculated results are consistent with actual measurements, therefore is suitable for the calculation of the possible evapotranspiration in

Table 1.Classification standard of drought and waterlog based on SPI.

\begin{tabular}{|c|c|c|c|}
\hline Index value & Category & Index value & Category \\
\hline$\geq 2.0$ & Extremely wet & $-1.0 \sim-1.49$ & Moderately dry \\
\hline $1.5 \sim 1.99$ & Very wet & $-1.5 \sim-1.99$ & Extremely dry \\
\hline $1.0 \sim 1.49$ & Moderately wet & $2.0 \leq$ & \\
\hline$-0.99 \sim 0.99$ & Near normal & & \\
\hline
\end{tabular}


Table 2. Dryness/wetness gradation of Palmer index.

\begin{tabular}{|c|c|c|c|}
\hline Index value & Category & Index value & Category \\
\hline$\geq 4.00$ & Extremely humid & $-1.00 \sim-1.99$ & Slight drought \\
\hline $3.00 \sim 3.99$ & Severely wet & $-2.00 \sim-2.99$ & Severe drought \\
\hline $2.00 \sim 2.99$ & Moderately humid & $-3.00 \sim-3.99$ & Extreme drought \\
\hline $1.00 \sim 1.99$ & Slightly moist & $\leq-4.00$ & \\
\hline$-0.99 \sim 0.99$ & Normal & & \\
\hline
\end{tabular}

the Palmer drought degree model in months. The specific calculation formula [17] is:

$$
E T_{O}=\frac{0.408 \Delta\left(R_{n}-G\right)+\gamma \frac{900}{T+273} U_{2}\left(e_{s}-e_{a}\right)}{\Delta+\gamma\left(1+0.34 U_{2}\right)}
$$

...where $E T_{O}$ is the potential evapotranspiration, $\mathrm{R}_{\mathrm{n}}$ is the net surface radiation, $\mathrm{G}$ is the soil heat flux, $\mathrm{T}$ is the average temperature, $U_{2}$ is the wind speed at a height of $2 \mathrm{~m}, \mathrm{e}_{\mathrm{s}}$ is the saturated water pressure, $\mathrm{e}_{\mathrm{a}}$ is the actual water pressure, and $\Delta$ is the slope of the saturated water vapor pressure curve, $\gamma$ is the wet and dry meter constant.

$E T_{o}$ Calculator (download URL http://www.fao.org/ $\mathrm{nr} /$ water/eto.html) is mainly used for the calculation of potential evapotranspiration $E T_{O}$ in this paper. The input meteorological data types are mainly sunshine hours, average temperature, average maximum temperature, average minimum temperature, average wind speed, average vapor pressure. The calculation steps are not repeated in this article since the calculation process of the Palmer drought severity index have already been elaborated in related researches. The specific calculation steps refer to relevant literature [18]. The PDSI drought and flood classification criteria are shown in Table 2.

\section{Results}

\section{Access to Dry and Wet Edges}

By the extraction of the feature space of research vegetation index (NDVI) and land temperature (LST) and fitting the dry and wet edge equations from 2008 to 2017 in central Yunnan, it could be seen that the dry edge showed a negative correlation, and the wet edge presented a relatively weak correlation (as shown in Fig. 6). The maximum LST divergence slope of NDVI was less than 0 , which indicated that the corresponding surface temperature decreased with the increase of vegetation index. On the contrary, the minimum LST dispersion slope of NDVI was greater than 0 , which indicated that the corresponding surface temperature increased gradually with the increase of vegetation index. It could be seen from the figure that the NDVILST feature spaces of 2008, 2011, 2014 and 2017 were obviously trapezoidal and triangular in shape, which was consistent with the theory of TVDI. The dry edge divergence was approximately linear, and $\mathrm{R}^{2}$ was more than 0.8 , and the fitting condition was better. However, in 2008 and 2011, the distribution of wet edge dispersion was more dispersed, and the fitting condition was worse than that of dry edge (Table 3). But the constructed feature space well reflected the relationship between vegetation coverage and surface temperature in central Yunnan.

\section{Classification of Drought Grades}

In the scope of agricultural drought, it is generally considered that the soil moisture content less than $40 \%$ of field capacity within $0 \sim 20 \mathrm{~cm}$ soil thickness is severe drought; less than $50 \%$, moderate drought; less than $60 \%$, mild drought; $60 \%-80 \%$, normal; and more than $80 \%$, moisture [19]. According to the definition of TVDI, when TVDI is 0 , soil water content is close to normal moist soil, TVDI is equal to 1 , then soil water content is close to wilting water content, and TVDI value is closer to 1 , indicating soil drought and water shortage. According to the classification of drought grades in the literature $[20,21]$, combined with the climatic and seasonal factors in the study area, the

Table 3. Dry and wet edge fitting equation for central Yunnan from 2008 to 2017.

\begin{tabular}{|c|c|c|c|c|}
\hline Time & Dy & $\mathrm{R}^{2}$ & Wy & $\mathrm{R}^{2}$ \\
\hline 2008 & $\mathrm{Dy}=47.80-28.64 * \mathrm{x}$ & 0.88 & $\mathrm{Wy}=-2.37+11.78^{*} \mathrm{x}$ & 0.47 \\
\hline 2011 & $\mathrm{Dy}=44.04-20.36 * \mathrm{x}$ & 0.92 & $\mathrm{Wy}=-0.08+21.69 * \mathrm{x}$ & 0.53 \\
\hline 2014 & $\mathrm{Dy}=55.69-19.36 * \mathrm{x}$ & 0.81 & $\mathrm{Wy}=14.85+4.31 * \mathrm{x}$ & 0.49 \\
\hline 2017 & $\mathrm{Dy}=51.17-22.11 * \mathrm{x}$ & 0.86 & $\mathrm{Wy}=-0.58+5.85 * \mathrm{x}$ & 0.53 \\
\hline
\end{tabular}


2008

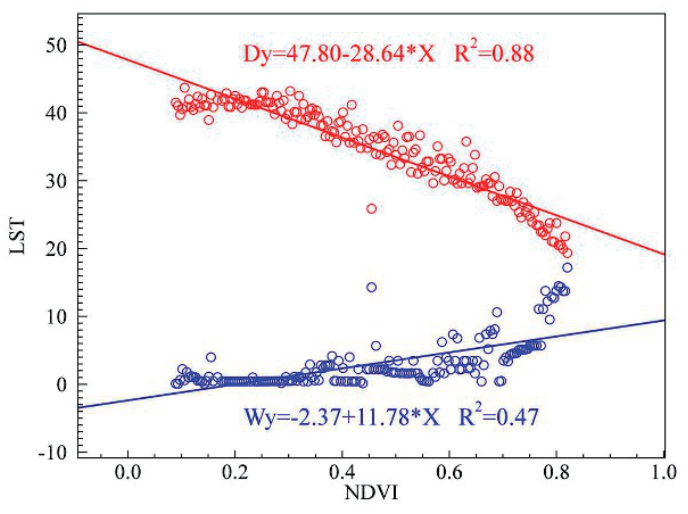

2014

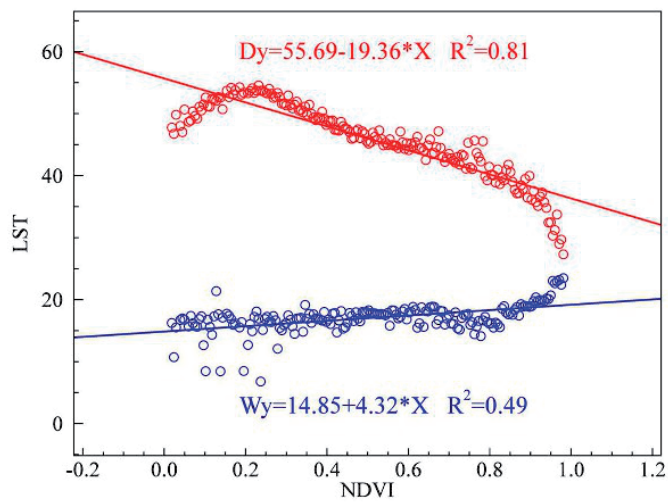

2011

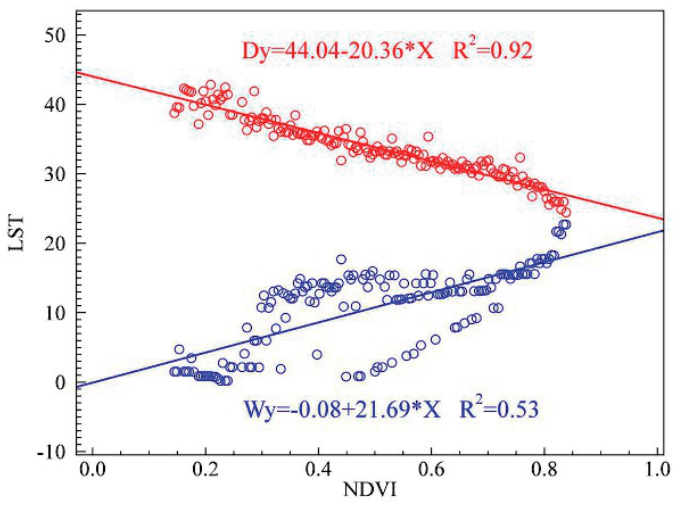

2017

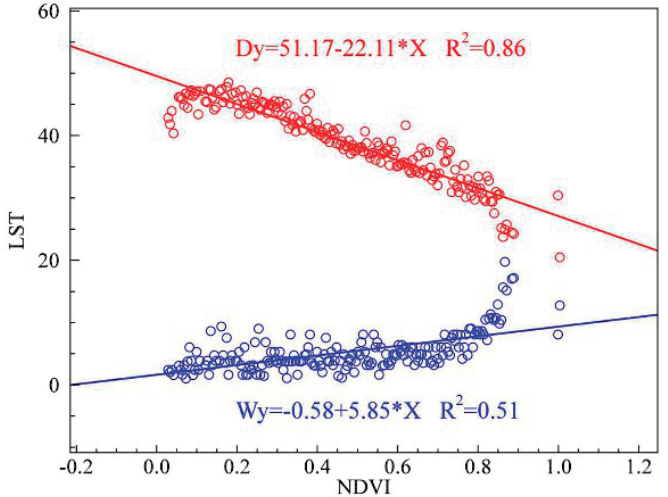

Fig. 6. Dry and wet edge fitting equation of NDVI-TS feature space in central Yunnan from 2008 to 2017.

Note: Dy is dry edge equation, Wy is wet edge equation.

grade of central Yunnan is divided into five categories: wet $(0 \sim 0.2)$, normal $(0.2 \sim 0.4)$, moderately dry $(0.4 \sim 0.6)$, dry (0.6 0.8), severe dry $(0.8 \sim 1)$, five categories, as shown in (Table 4). The calculation of the area and proportion of different drought levels in the study area was executed based on area statistics.

\section{Model Suitability Verification}

A comprehensive usage of Standardized Precipitation Index (SPI), Palmer drought severity index (PDSI) and Potential Evapotranspiration (PET) were executed for verification of the applicability of
Table 5. Change trend of average TVDI in central Yunnan from 2008 to 2017.

\begin{tabular}{|c|c|c|c|c|}
\hline Years & 2008 & 2011 & 2014 & 2017 \\
\hline TVDI Mean & 0.6027 & 0.5856 & 0.5839 & 0.5793 \\
\hline Std Dev & 0.11 & 0.10 & 0.13 & 0.09 \\
\hline
\end{tabular}

the TVDI index in central Yunnan. SPI is commonly used for drought assessment based on rainfall data from meteorological ground stations. Wang [22] et al. calculated the multi-scale SPI of the research area from

Table 4. Classification criteria and area ratio of drought grades in the Central Yunnan.

\begin{tabular}{|c|c|c|c|c|c|c|c|c|c|}
\hline \multirow{2}{*}{ TVDI Interval } & \multirow{2}{*}{ Drought level } & \multicolumn{2}{|c|}{20008} & \multicolumn{2}{|c|}{2011} & \multicolumn{2}{|c|}{2014} & \multicolumn{2}{c|}{2017} \\
\cline { 3 - 10 } & & Area $/ \mathrm{km}^{2}$ & Scale $/ \%$ & Area $/ \mathrm{km}^{2}$ & Scale $/ \%$ & Area $/ \mathrm{km}^{2}$ & Scale $/ \%$ & Area $/ \mathrm{km}^{2}$ & Scale/\% \\
\hline $0.0 \leq \mathrm{TVDI}<0.2$ & Wet & 310 & 0.31 & 1100 & 1.10 & 590 & 0.59 & 360 & 0.36 \\
\hline $0.2 \leq \mathrm{TVDI}<0.4$ & Normal & 2160 & 2.16 & 2390 & 2.39 & 9203 & 9.20 & 2410 & 2.41 \\
\hline $0.4 \leq \mathrm{TVDI}<0.6$ & Moderately dry & 27310 & 27.31 & 52980 & 52.98 & 42452 & 42.45 & 48550 & 48.55 \\
\hline $0.6 \leq \mathrm{TVDI}<0.8$ & Dry & 63480 & 63.48 & 42280 & 42.28 & 44041 & 44.04 & 47170 & 47.17 \\
\hline $0.8 \leq \mathrm{TVDI}<1.0$ & Severe dry & 6730 & 6.73 & 1250 & 1.25 & 3714 & 3.71 & 1500 & 1.50 \\
\hline
\end{tabular}




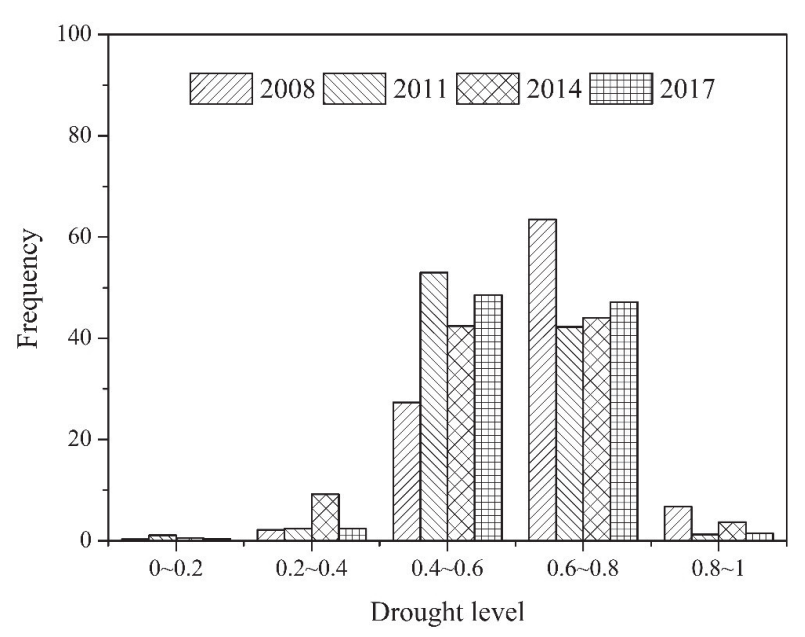

Fig. 7. Change of drought grade area in central Yunnan from 2008 to 2017.

ground based rainfall data to verify the constructed microwave remote sensing temperature vegetation drought applicability of the index (TMVDI) in Sichuan Province. The Palmer drought severity index (PDSI) comprehensively considers precipitation, soil water content, runoff and potential evapotranspiration, and is a good proxy indicator for the degree of drought. Liu [23] compared the ability of PDSI and TVDI to reflect drought based on MODIS data and meteorological data, and the results showed that the two are consistent.
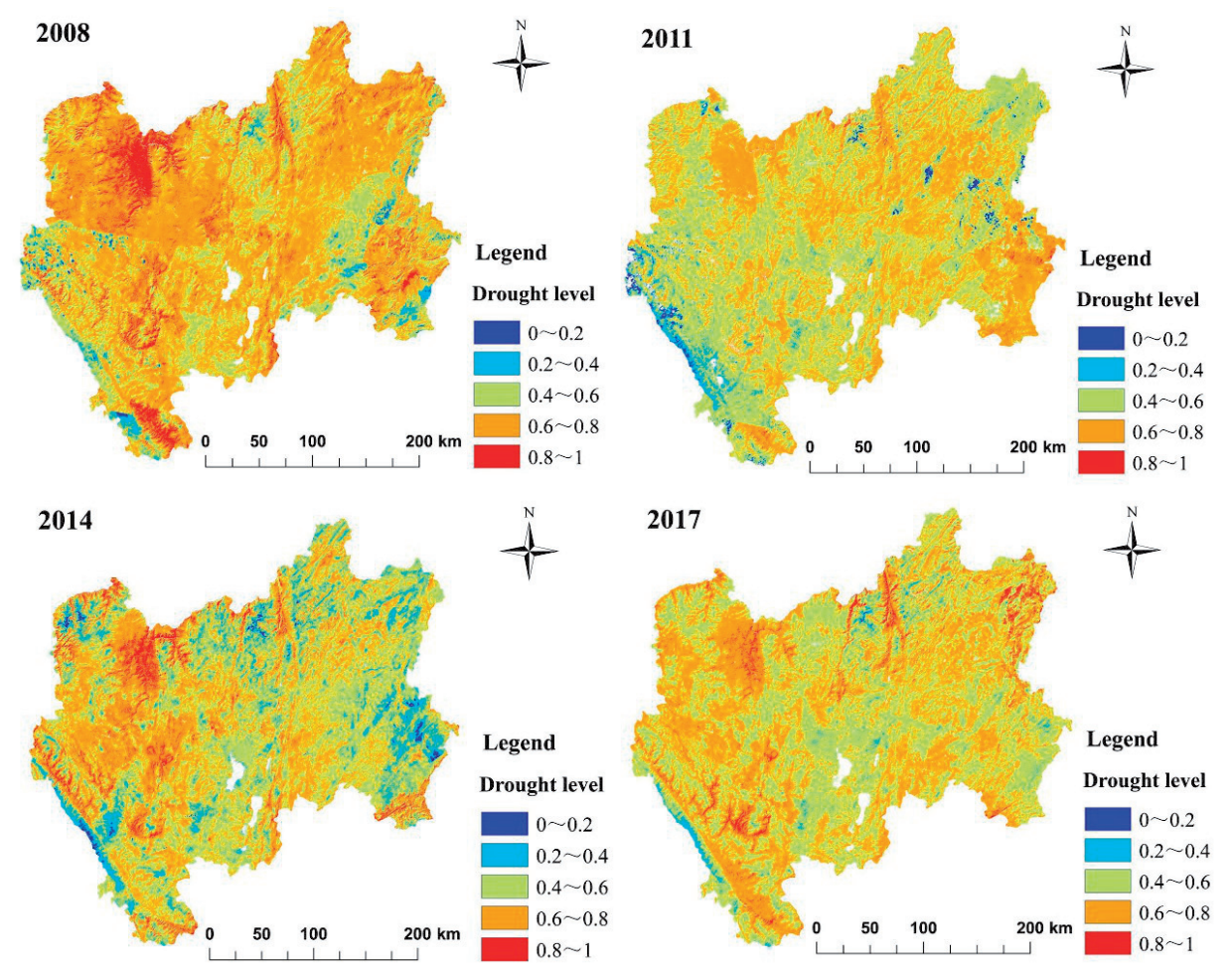

Fig. 8. Space-time variation of TVDI in central Yunnan from 2008 to 2017.

This paper is based on the collected monthly average weather data of 39 meteorological stations in four cities and prefectures in central Yunnan in 2011, including rainfall, sunshine hours, average temperature, average maximum temperature, average minimum temperature, average wind speed and average vapor pressure. The SPI, PDSI, and PET values of the central Yunnan area on a time scale of one month are obtained by simulation, and the TVDI values of 39 meteorological stations in central Yunnan in 2011 were obtained from the Spatial Analyst module of Arcgis. Correlation analyses were then carried out by using the meteorological drought index value and TVDI value in central Yunnan. The results showed that:

Using the TVDI and SPI, PDSI and PET of 39 sites in central Yunnan, the correlation analysis was carried out, the correlation coefficients are $-0.43,-0.45,0.5$ (there is a positive correlation between PET and TVDI), and the significance test results are $P=0.00028$, $P=0.00039, P=0.00017$ and $P<0.05$, which proves that TVDI has a significant correlation with SPI, PDSI, PET.

Drought is caused by a combination of natural and human factors. As central Yunnan region is located in the Yunnan-Guizhou plateau, the monthly average rainfall in this region is less than the evaporation amount through the comparison of the precipitation and evaporation amount in the meteorological data (Fig. 2). Among them, most of the meteorological stations in Chuxiong City and Yuxi City are typical, and the evaporation amount is much larger than the rainfall amount. Besides, in eastern central Yunnan karst geomorphology were widely distributed, in which rock 

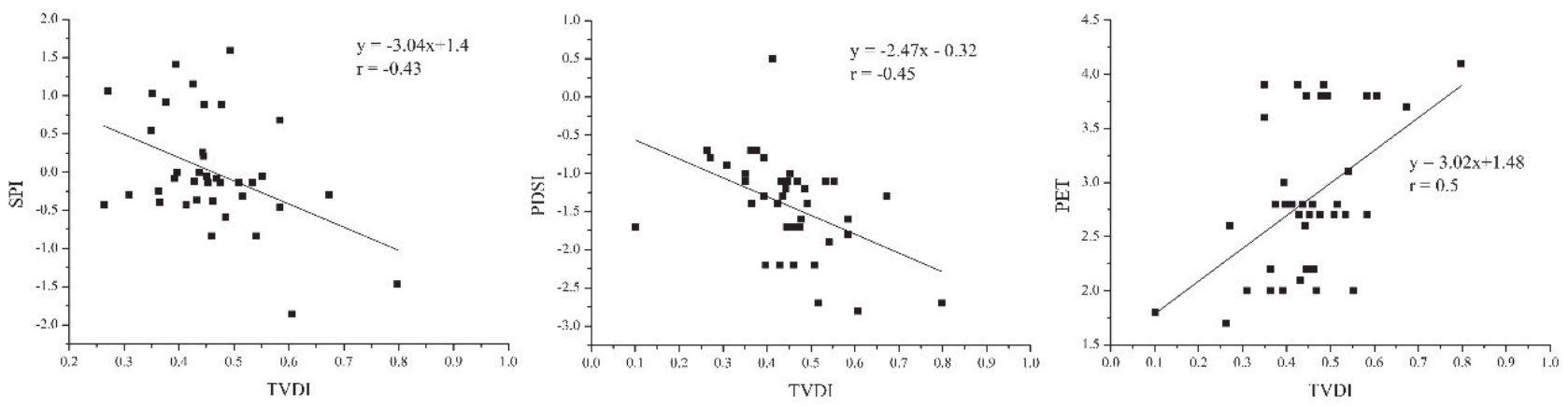

Fig. 9. Correlation analysis between TVDI and SPI, PDSI, PET.

bare karst area rate is high, the shallow soil layer, soil water is poorer, and strong rock leakage, the surface of the water deficit frequent [24]. Therefore, the single use of rainfall data does not reflect the actual local drought conditions well, and will have a certain impact on the model verification results. It is concluded that integrated use of SPI, PDSI, and PET based on meteorological data to verify the regional applicability of the TVDI model is more reliable. In addition, several scholars [25-28] used TVDI model to monitor drought in Yunnan and central Yunnan and achieved better results. Comparing those spatial distributions with drought monitoring in this paper, the results showed that the regions at drought level all year round are mainly distributed in most area of Chuxiong, areas covered by low vegetation, concentrated farmland distribution areas and river valleys. Areas less affected by spring drought were in areas with higher vegetation coverage, such as Ailao Mountain in the southwest. In conclusion, TVDI model is suitable for drought monitoring in Yunnan and central Yunnan.

\section{Analysis of Temporal and Spatial Trends of Drought}

Judging from Table 4 and Fig. 8, the area and distribution of drought grades in central Yunnan in 2008 2017 have changed significantly, and the proportion of drought grades in humid areas decreased from $0.31 \%$ in 2008 , rose to $1.1 \%$ in 2011 , and then fell to 0.59 percent in 2014 and continue reduce to 0.36 percent in 2017, with less volatility.

Spatial growth in 2008 mainly distributed in the southern part of the Ailao Mountain range in the southwest of central Yunnan and northern Jiaozi Snow Mountain. Affected by cloud cover in 2011, it expanded to the eastern addition to the Jiaozi Snow Mountain and the Ailao Mountain. In 2014 it is located in the middle of the Ailao Mountains, Jiaozi Snow Mountain in the north, Shaobi in the northwest of Chuxiong and southeast parts of Qujing, and mainly in the snow mountain of Jiaozi in 2017. The reasons for the changes in humid areas are mainly the lower surface temperature and higher vegetation coverage due to higher altitude and sufficient rainfall.
The area with normal drought level also shows a fluctuating trend. It increased slightly from $2,160 \mathrm{~km}^{2}$ in 2008 to $2,390 \mathrm{~km}^{2}$ in 2011 and rapidly to $6,850 \mathrm{~km}^{2}$ in 2014, which is a significant increase. The figure of 2017 has dropped significantly to $2,410 \mathrm{~km}^{2}$ afterwards; In 2008, it was mainly distributed in the southern part of Ailao Mountain in the southwest of central Yunnan, the snow mountain of Jiaozi in the north, the whole part of the Ailao Mountains in the southwest of the region in 2011, a small part of central Yunnan and some parts of the northeast of it. Compared with 2011, the new spatial growth areas in 2014 mainly distributed in northwest Chuxiong, in northern central Yunnan and northeast Qujing, and in 2017 in central part of the Ailao Mountains and a few areas of the snow mountain of Jiaozi. According to the rainfall statistics and the spatio-temporal distribution of surface temperature, the main reasons for the change are increased local rainfall, lower surface temperature and lower evaporation.

The proportion of drought grade with moderately drought showed a trend of rapid growth and then decreased slowly, accounting for $27310 \mathrm{~km}^{2}$ in 2008 and $52980 \mathrm{~km}^{2}$ in 2017 , a relatively large increase, and a significantly reduced to $42452 \mathrm{~km}^{2}$, in 2014 and then to $48550 \mathrm{~km}^{2}$, in 2017. Spatial change in 2008 mainly distributed in northeast central, southern and northern Yunnan, in 2011 distributed widely, among which the southeast, north, central, south and northwest of the main distribution area and spread to the surrounding trend. It was mainly distributed in northern and central Yunnan in 2014, mainly in central and southeastern Yunnan in 2017 compared with 2008. The main reason is that the increased in rainfall and the weakening of evaporation had led to the transition from drought to light drought in most areas of central Yunnan. At the same time, the main land use types in light drought areas are grassland, shrubs and farmland, and the vegetation coverage is low. Also soil moisture retention has a greater impact.

The proportion of drought grades decreased rapidly in 2008, followed by a dynamic trend of slight growth in 2017, with a sharp decline in area from $63480 \mathrm{~km}^{2}$, in 2008 to $42280 \mathrm{~km}^{2}$ in 2011 , and had slight raised from $44041 \mathrm{~km}^{2}$ in 2014 to $47170 \mathrm{~km}^{2}$ in 2017; spatiality wise, the distribution in 2008 was 
obviously superior to other grades, mainly distributed in northwest, northeast and southeast central Yunnan, in 2011, in northwest, southeast, most of Chuxiong in 2014, and northern part of Yuxi; mainly in northern part of Yuxi and Chuxiong in 2014. In 2017, except for the northwest, the distribution of the southwest was long and the south end of Ailao Mountain was wide, and the east was scattered. The main reason for the change was that the climatic change tended to be stable, and the rainfall increased gradually resulting in the transformation from drought to moderate drought in a large area. In addition, areas that have been arid for a long time are mostly bare land without vegetation cover and urban built-up areas. Compared with other land use types, the surface temperature is higher, the amount of evaporation is greater, and the soil moisture is difficult to maintain. Take Chuxiong Prefecture in the west as an example, the temperature in this region is high, and the evaporation has been much higher than the rainfall for a long time. The low vegetation coverage in the area and the bare ground result in low soil moisture content. Under the combined influence of multiple factors, Chuxiong Prefecture Droughts occur frequently and water shortages are serious, with Yuanmou City of Chuxiong Prefecture being the most typical.

Severe drought grade area showed a fluctuating downward trend, from $6730 \mathrm{~km}^{2}$ in 2008 to $1250 \mathrm{~km}^{2}$ in 2011, a slight increase to $3714 \mathrm{~km}^{2}$ in 2014 , and a continued decline to $1500 \mathrm{~km}^{2}$ in 2017. The area of severe drought in central Yunnan was relatively small, with the spatial distribution of 2008 mainly in the northwest, the southwest and the northern valley, and in the northern valley and the southeastern karst concentration in 2011. In 2014, it was mainly distributed in the northern and central regions of Chuxiong and the Yuanjiang River valley in the western part of the country. In 2017, it was scattered in the southwest, the northern valley and the eastern part of the valley. The main reason was the increase of rainfall in Yunnan Province in recent years, especially in the eastern, northern and eastern parts of central Yunnan. The temperature in Chuxiong Prefecture in the west was high, the evaporation was much higher than the rainfall over a long period of time, and the vegetation cover in the area was relatively low. Under the comprehensive influence of multiple factors, drought occurred frequently in Chuxiong Prefecture and water shortage was serious, such as Yuanmou County, Chuxiong Prefecture.

The increase in precipitation and the stability of the climate have led to a slightly reduced in the average TVDI from 0.6027 to $0.5856,0.5839$ in central Yunnan from 2008 to 2014, and to 0.5793 in 2017 (Table 5). On the whole, the drought grade decreased slowly from drought to moderate drought, and the drought stress decreased, but it was still near the edge of drought, and the drought situation in the area was not optimistic. The spatial and temporal distribution of drought is affected by the natural geographic environment (including rainfall, temperature, vegetation coverage, altitude and topography), and human activities (mainly land use types). Among them, areas with humid and normal drought levels are mainly distributed in areas with better vegetation coverage and higher elevations; Light droughts are mainly distributed in areas such as grasslands, shrubs and farmlands with low vegetation coverage. Soil moisture content is greatly affected by rainfall and temperature. Droughts and severe droughts are stably distributed in the river valley area for a long time. The river valleys in the study area are all dry and hot valleys, with low altitude and high temperature. The two sides of the valley are mostly mudflats, with almost no vegetation coverage and extremely poor soil water retention.

\section{Discussion}

Data Aspects

Because the cloud amount of Landsat series data in the study area is on the high side and most of them are thick clouds, although the effect of cloud is removed as far as possible by the method of mask, it is not completely eliminated. Furthermore, the range of each scene image of Landsat series data is limited, and the amount of cloud in the east and southwest of Yunnan is large, so the selected data is not in the same time, so it has some limitations. In the future, we will continue to improve the mask treatment of cloud cover, minimize its influence on vegetation index and surface temperature, and consider choosing the data with large coverage such as MODIS. At the same time, this research year is 2008 2017, the research time is relatively short, also needs to continue to expand the research time scale.

\section{Drought Monitoring}

In this paper, the drought index is graded by inversion of the temperature index Drought Index TVDI of vegetation index and surface temperature, but the drought is the result of a combination of various factors. In the future, it is necessary to comprehensively consider the underlying surface condition (topography, surface cover type, soil) and meteorological conditions (temperature, evaporation, sunshine hours, etc.) as well as to increase the accuracy in the analysis of the characteristics of drought spatial and temporal changes and drought dominant factors in the study area.

\section{Verification}

Because of the large area of study, it is difficult to obtain the measured data of soil moisture, and will consume a lot of manpower, material and financial resources. Therefore, SPI, PDSI and PEI based on meteorological data are used to verify the regional 
applicability of the TVDI model. Furthermore, there are some limitations due to the instantaneous rainfall and the obvious lag of soil moisture change. Other drought monitoring indicators, such as soil moisture, crop yield, leaf area index and so on, could be considered.

\section{Conclusions}

The main contents are as follows:

1. Using Landsat data to extract the normalized difference vegetation index and the land surface temperature in central Yunnan are extracted from Landsat data, and the surface drought status is inversed by the characteristic spatial relationship between NDVI and LST. Through the extraction of water and clouds, the effects of water body and cloud on normalized vegetation index and surface temperature are reduced as much as possible, and the ideal dry and wet edge equations are obtained.

2. The temporal and spatial variation trend of drought in central Yunnan has changed from drought in 2008 to mild drought in 2017, drought in middle and central Yunnan has changed from severe drought to drought and moderately drought in space, from moderately drought and drought partial to normal in central Yunnan, mostly to mild drought. Parts of the east and south developed from drought, mild drought to weak drought. But the whole area of central Yunnan is still close to the state of drought, and the situation of drought in this area is not optimistic.

3. Using the monthly average meteorological data of 39 stations in central Yunnan, the correlation analysis between TVDI and SPI, PDSI and PEI showed that TVDI has a correlation with the three meteorological drought indices, indicating that TVDI has a better performance in central Yunnan. Application of TVDI is feasible for classification of drought levels in central Yunnan and the monitoring the temporal and spatial characteristics of drought distribution in the region.

\section{Acknowledgements}

This research was funded by Multi-government International Science and Technology Innovation Cooperation Key Project of National Key Research and Development Program of China for the "Environmental monitoring and assessment of land use/land cover change impact on ecological security using geospatial technologies"[grant number 2018YFE0184300], and by Erasmus + Capacity Building in Higher Education of the Education, Audiovisual and Culture Executive Agency (EACEA) for the "Innovation on Remote Sensing Education and Learning", grant number 586037-EPP1-2017-1-HU-EPPKA2-CBHE-JP. We would like to express our sincere gratitude to the Erasmus+ Capacity Building in Higher Education of the Education,
Audiovisual and Culture Executive Agency (EACEA) for its grant.

\section{Conflict of Interest}

The authors declare no conflict of interest.

\section{References}

1. CHEN B., ZHANG. X.X., HUA K. Application Study of Temperature Vegetation Drought Index (TVDI) in Grassland Drought Monitoring. Arid Area Geography (Chinese Edition), 36 (5), 930, 2013.

2. QIN Z.H., TANG H.J., LI W.J. Research frontiers of the impact of climate change on my country's grain production system.China Agricultural Resources and Regional Planning, 36 (01), 01, 2015.

3. ULAN T.Y., YU L.F., WU L., BAO J.W., XU H.T. Drought Analysis of Hetao Irrigation District Based on Landsat8 TVDI - A Case Study of Linhe District.China Agricultural Resources and Regional Planning, 38 (05), 123, 2017.

4. LI H., WANG P.X. The Condition Monitoring and Comparative Analysis of Conditional Vegetation Temperature Index Based on Terra-MODIS and NOAAAVHRR Data.Arid area resources and environment, 27 (3), 61, 2013.

5. YU Y.H., W J.L., LI X.P. Drought monitoring in central Yunnan based on MODIS data. Journal of Irrigation and Drainage, 37 (11), 93, 2018.

6. PANG S.F., WEI W., GUO Z.C., ZHANG J.,ZHE B.B. Characteristics of agricultural drought and its influencing factors in Gansu Province based on TVDI. Journal of Ecology, 38 (6), 1849, 2019.

7. YU M., CHENG M.H. Drought Monitoring in Heilongjiang Province Based on NDVI-Ts Feature Space. Chinese Journal of Applied Meteorology, 21 (02), 221, 2010.

8. ZHANG Z., DING J.L., YAN X.Y., et al. Remote sensing monitoring of drought in typical oasis of Turkmenistan based on temperature vegetation drought index. Journal of Ecology, 32 (8), 2172, 2013.

9. LIU Y., YUE H., HOU E.K. Application of MODIS data in drought monitoring in Shaanxi Province. Remote Sensing for Land \& Resources, 31 (2), 172, 2019.

10. HAN X.X., CHEN X.L., QIN C., FENG L.,TIAN L.Q. Research on drought remote sensing monitoring based on HJ-1A/1B satellite TVDI: Taking Poyang Lake Basin as an example. Journal of Central China Normal University (Natural Science Edition), 48 (2), 1000, 2014.

11. YAN F., WANG Y.J., WU B. Differences in spatial drought monitoring of temperature-vegetation index characteristics on multiple time scales. Geography Science, 34 (08), 987, 2014.

12. SANDHOLT, RASMUSSEN K., ANDERSEN J. A simple interpretation of the surface temperature/ vegetation index space for assessment of surface moisture status. Remote Sensing of Environment,79 (2), 213,2002.

13. MCKEE T.B., DOESKEN N.J., KLEIST J. The relationship of drought frequency and duration to time scales. 1993.

14. State Administration of Quality Supervision, Inspection and Quarantine of the People's Republic of China, China National Standardization Administration. GB/T20481- 
2006 Meteorological Drought Level. Beijing: China Standard Press, 2006.

15. HUANG W.H., YANG X.G., LI M.S., ZHANG X.Y., WANG M.T., DAI Y.W., MA J.H. Seasonal drought evolution in southern China based on standardized precipitation index in recent 58a. Journal of Agricultural Engineering, 25 (7), 60, 2010.

16. PALMER W.C. Meteorological Drought.U.S. Weather Bureau, Res. Pap, 45, 1965.

17. LIU W.W., AN S.Q., LIU G.S., et al. Further revision of Palmer drought degree model. Journal of Applied Meteorology, 15 (02), 207, 2004.

18. CHEN Y.T., CHANG J.X., HUANG S.Z., HUANG Y.M.,GUO A.J. Drought characteristics in the Weihe River Basin based on PDSI. Journal of Natural Disasters, 23 (05), 29, 2014.

19. TIAN G.L., LIU Q.H, CHEN L.F. Thermal infrared remote sensing. Electronic Industry Press, 88, 2014.

20. YAN N., LI D.K., DU J.W., YAN J.P. Shaanxi drought monitoring based on MODIS product LST/NDVI/EVI. Journal of Natural Disasters, 19 (04), 178, 2010.

21. YI Y.H., YANG D.W., LIU Z.Y., WANG J.X. Application of multi-temporal medium-resolution satellite imagery in drought monitoring in eastern Sichuan and Chongqing in 2006. Journal of Hydraulic Engineering, 39 (04), 490, 2008.
22. WANG Y.Q., SHI J.C., LIU Z.H., FENG W.L.,QIU Y.B. Application of microwave vegetation index in drought monitoring. Journal of Remote Sensing, 18 (04), 843, 2014.

23. LIU J.B. Research on drought monitoring in Sichuan Province based on improved linear dual-source remote sensing evapotranspiration model. Chengdu University of Technology, 2018.

24. LI Z., GAO K.M., LIU J.C., LIANG Q.H., TAO J.P. Growth response of two herbs to dry-wet alternation and $\mathrm{N}$ addition in Southwest Karst area. Journal of Ecology, $\mathbf{3 6}$ (11), 3372, 2016.

25. LUO Y.Q. Research on remote sensing drought monitoring based on TVDI model. Yunnan Normal University, 2015.

26. LONG X.M., WANG L., YANG R., TIAN L. Remote sensing monitoring of drought in Yunnan based on temperature vegetation drought index. China Rural Water and Hydropower 11, 141, 2012.

27. WANG H., YANG Z.X., WANG L., LIU Y.P., SONG Y., CAO J. Application of TVDI in drought monitoring in Yunnan in 2009/2010. Journal of Yunnan University (Natural Science Edition), 36 (1), 59, 2014.

28. CAO Y., HU W.Q., YAN P.D. Remote sensing monitoring of drought in Yunnan based on temperature vegetation drought index (TVDI). Engineering Survey, 44 (01),73, 2016. 
